\title{
Comment on basal epithelial stem cells as efficient targets for prostate cancer initiation
}

\author{
Letitia Wong and Wade Bushman*
}

\begin{abstract}
Human prostate adenocarcinoma is a multicentric disease with histological heterogeneity and variation in biological features. The present study showed that a cell with stem properties undergoing oncogenic transformation can produce prostate mouse lesions with varied histological phenotypes that resemble different grades of human prostate cancer. This powerful observation is consistent with the notion that a complex spectrum of prostate neoplasms may arise from a common cell of origin, facilitating future studies to understand the development of prostate disease. Even so, it must be noted that there is no conclusive evidence that stem cells are the source of human prostate cancer, and therefore additional studies are required comparing features and natural history of tumors generated by this approach with the process of oncogenesis in the human prostate.
\end{abstract}

Adenocarcinoma of the prostate is an epithelial malignancy that occurs in aging men. The normal prostatic epithelium is a pseudostratified epithelium with secretory luminal cells and interspersed basal cells. Prostate cancer generally exhibits a luminal cell morphology with a distinct absence of basal cells. Tumors are often multifocal and exhibit considerable variation in histologic morphology and grade $[1,2]$. The present study identified a select group of basal cells with stem cell properties in the mouse prostate that is capable of cancer initiation following oncogenic transformation. The resulting tumors exhibit a range of histologic morphologies - depending upon the genetic mutations introduced - that phenocopy the varied appearance of human prostate cancer. This is an intriguing observation showing that the same cell of origin can yield a range of tumor morphologies and grades depending on the genetic changes inflicted.

*Correspondence: bushman@urology.wisc.edu

UW School of Medicine and Public Health, Department of Urology, K6/563, 2233 Clinical Science Center-K6, 600 Highland Ave, Madison WI 53792, USA
In a related study, Shen and colleagues reported that a rare population of castration-resistant NKx3.1-expressing cells with stem cell characteristics is capable of initiating formation of carcinoma upon deletion of the tumor suppressor gene PTEN [3]. There is strong evidence for the existence of tissue-specific stem cells in the prostate, capable of self-renewal and differentiation into the full range of prostate epithelial cell types $[4,5]$, and it has been speculated that these stem cells and/or closely related progenitor cells may be the progenitor for human prostate cancer. The work on tissue-specific stem cells in the prostate lends credence to that speculation, and resonates with a previous report that cells present in normal human prostate epithelium with a basal phenotype and stem cell properties are also present in human prostate cancer [6]. There is as yet, however, no conclusive evidence that stem/progenitor cells are in fact the source of human prostate cancer.

The multicentric and variegated histology of prostate cancer within a single prostate gland makes identifying the cell of origin a complicated and daunting challenge. Do the multicentric lesions share a common origin? Does prostate cancer begin as a low-grade lesion that spins off successively higher-grade tumor clones? Or do multiple low-grade and high-grade lesions arise independently within the same gland? Obviously, the answers to these questions will determine how we interpret studies examining the tumor-forming ability in a mouse model.

Recent work has implicated chronic inflammation in the genesis of prostate cancer $[7,8]$. Areas of chronic inflammation associated with atrophic-appearing yet hyperproliferative epithelium (proliferative inflammatory atrophy) commonly appear in association with foci of prostatic intraepithelial neoplasia and cancer in the peripheral zone of the prostate [9]. This has led to speculation that the origin of cancer is the proliferative epithelium in these atrophic glands. The correlation of the basal cells in the present study by Witte and colleagues or of the luminal cells in the study by Shen and colleagues to the epithelial cells in proliferative inflammatory atrophy is unknown but is an intriguing question.

Finally, it must be noted that a weakness of all animalbased studies focusing on tumor formation is a definition 
of prostate cancer that is inherently incomplete. Human prostate cancer is defined not only by histologic criteria but also by a natural history that includes local invasion, characteristic patterns of lymph node and bone metastasis and a general pattern of initial androgen dependence giving way to androgen independence in advanced disease $[1,2]$. The finding that genetic alterations of a select group of basal cells produces prostate lesions with variation in histological morphology that resemble various grades of prostate cancer is a powerful observation - but an observation that needs correlative studies with the process of oncogenesis in the human prostate and also further studies to elucidate the natural history and androgen dependence of the tumors generated by this approach.

\section{Competing interests}

The authors declare that they have no competing interests.

Published: 8 June 2010

\section{References}

1. Nelson WG, De Marzo AM, Isaacs WB: Prostate cancer. N Engl J Med 2003, 349:366-381.

2. Weiss MA, Mills SE: Neoplastic lesions of the prostate and seminal vesicles. In Genitourinary Tract Pathology. New York: Raven Press; 1993:14.1-14.8.
3. Wang X, Kruithof-de Julio M, Economides KD, Walker D, Yu H, Halili MV, Hu YP Price SM, Abate-Shen C, Shen MM: A luminal epithelial stem cell that is a cell of origin for prostate cancer. Nature 2009, 461:495-500.

4. Sugimura Y, Cunha G, Donjacour A: Morphological and histological study of castration-induced degeneration and androgen-induced regeneration in the mouse prostate. Biol Reprod 1986, 34:973-983.

5. Tsujimura A, Koikawa Y, Salm S, Takao T, Coetzee S, Moscatelli D, Shapiro E, Lepor H, Sun TT, Wilson EL: Proximal location of mouse prostate epithelial stem cells: a model of prostatic homeostasis. J Cell Bio/ 2002, 157:1257-1265.

6. Collins AT, Berry PA, Hyde C, Stower MJ, Maitland NJ: Prospective identification of tumorigenic prostate cancer stem cells. Cancer Res 2005, 65:10946-10951.

7. De Marzo AM, Marchi VL, Epstein Jl, Nelson WG: Proliferative inflammatory atrophy of the prostate: implications for prostatic carcinogenesis. Am J Pathol 1999, 155:1985-1992.

8. Wang W, Bergh A, Damber JE: Morphogical transition of proliferative inflammatory atrophy to high-grade intraepithelial neoplasia and cancer in human prostate. Prostate 2009, 69:1378-1386.

9. De Marzo AM, Platz EA, Sutcliffe S, Xu J, Grönberg H, Drake CG, Nakai Y, Isaacs WB, Nelson WG: Inflammation of prostate carcinogenesis. Nat Rev Cancer 2007, 7:256-269.

\section{doi:10.1186/scrt16}

Cite this article as: Wong L, Bushman W: Comment on basal epithelial stem cells targets for prostate cancer initiation. Stem Cell Research \& Therapy 2010, 1:16. 